\title{
Monitoring of carbon steels welded joints by magnetic Barkhausen noise
}

\author{
Monitoreo de uniones soldadas de acero al carbono usando \\ el ruido magnético de Barkhausen \\ Claudia P. Serna-Giraldo ${ }^{1} \quad$ Linilson R. Padovese ${ }^{2}$ \\ Recibido 26 de agosto de 2013, aceptado 27 de noviembre de 2014 \\ Received: August 26, $2013 \quad$ Accepted: November 27, 2014
}

\begin{abstract}
When a variable magnetic field is applied to a ferromagnetic material, it has been observed that, next to the coercive field $\left(\mathrm{H}_{\mathrm{c}}\right)$, rise in induction (B) takes place through abrupt jumps known as Barkhausen jumps. In this research, the microstructure variation in carbon steel welded joints was monitored by the Magnetic Barkhausen Noise (MBN). The samples were welded by SMAW process, in which both one-pass and two-pass were applied. Microhardness and microstructure were also characterized. The MBN signal was measured and analysed by means of several frequency and time domain parameters. Furthermore, maps of the welded steel surfaces were plotted. The variation of the MBN parameters was correlated to those of the microhardness and microstructure. The results allowed identifying a heat-affected zone (HAZ) of the welded joint using the MBN signals.
\end{abstract}

Keywords: Magnetic Barkhausen noise, carbon steel welding, non-destructive magnetic testing, signal analysis, heat-affected zone (HAZ).

\section{RESUMEN}

Cuando un campo magnético variable se aplica a un material ferromagnético, se ha observado que cerca al campo coercitivo $\left(H_{c}\right)$ ocurre un aumento en la inducción $(B)$ de forma abrupta a manera de saltos conocidos como saltos de Barhausen. En esta investigación la variación de la microestructura en uniones soldadas de aceros al carbono fue monitoreada usando el Ruido Magnético de Barkhausen $(R M B)$. Las muestras fueron soldadas por el proceso SMAW, con aplicación de uno y dos pases de soldadura. Se caracterizaron la microdureza y la microestructura y se hicieron mediciones de RMB. Esta señal de RMB fue analizada utilizando varios parámetros en los dominios del tiempo y de la frecuencia, y fueron levantados mapas superficiales de los aceros soldados. La variación de los parámetros de RMB fue correlacionada con los cambios en la microestructura y la microdureza. Los resultados permitieron identificar la zona afectada térmicamente de la unión soldada usando las señales de RMB.

Palabras clave: Ruido Magnético de Barkhausen, soldadura de aceros al carbono, ensayos no destructivos magnéticos, análisis de señales, zona afectada térmicamente.

\section{INTRODUCTION}

Ferromagnetic materials that are submitted to variable magnetic field experience a rise induction (B) close to the coercive field $(\mathrm{Hc})$. This discontinuous increment represented as an abrupt jump is called Barkhausen jump. Barkhausen jumps have been explained by the interaction between the domain wall

\footnotetext{
1 Departamento de Ingeniería Metalúrgica y de Materiales. Facultad de Ingeniería. Universidad de Antioquia. Calle 67 № 53-108, Of. 18-136. Medellín, Colombia. E-mail: claserna@udea.edu.co

2 Departamento de Engenharia Mecânica. Escola Politécnica. Universidade de São Paulo. Av. Prof. Mello Moraes, 2231, CEP 05508-900. São Paulo, Brasil. E-mail: 1rpadove@usp.br
} 
movements and the constraints to these movements in the pinning sites, which are constituted by material imperfections such as dislocations, grain boundaries and precipitates [1]. If a coil is placed next to the sample surface when domain wall movements take place, the Barkhausen emission will be detected as electric tension pulsations.

The magnetic Barkhausen noise (MBN) depends not only on the parameters used during magnetization, such as frequency [1-3] and magnetization intensity [4-5], but also on material characteristics such as grain size [6-9], carbon content [10-11] and on the state of stress [12-13].

This dependence allows using the $\mathrm{MBN}$ as a non-destructive technique in several industrial applications, such as characterization of mechanical and thermal degradation, quality control of mechanized surfaces, residual stress, and surface heat treatment analysis. The need for non-destructive techniques for welded joints quality control is well known, particularly in the oil/gas sector. In carbon steel welded joints, the microstructure varies from the center of the fusion zone to the parent metal as a consequence of applied thermal cycles. In this context, the fusion zone can be identified (FZ), which presents typical solidification microstructures as well as a heat-affected zone (HAZ) where the microstructure variation is a response to transformation in the solid state due to high temperatures of the process [14-15].

One of the MBN potentialities is its usefulness as a monitoring technique for detection of structural variations introduced by heat treatment or by the presence of defects in welded joints. Some studies of MBN in welding were done by using simulated weld microstructures by special designed heat treatments [16-18], while others have been accomplished in real-welded surfaces aiming to evaluate post-welding thermal treatment effects [19] or the wear performance of the welded joints [20-21]. This work presents the ability of the MBN for the identification of the microstructure gradient of actual A36 carbon steel welded joints.

\section{EXPERIMENTAL METHODS AND MATERIALS}

The studied material is an A36 ASTM steel plate of commercial structural, $6 \mathrm{~mm}$ thick. The steel chemical composition, presented in Table 1, was obtained through optical emission spectrometry.

Table 1. Chemical composition of A36 ASTM structural steel.

\begin{tabular}{|c|c|c|c|c|}
\hline$\% \mathrm{Fe}$ & $\% \mathrm{C}$ & $\% \mathrm{Si}$ & $\% \mathrm{Mn}$ & $\% \mathrm{~S}$ \\
\hline 98,323 & 0,111 & 0,308 & 0,989 & 0,032 \\
\hline$\% \mathrm{P}$ & $\% \mathrm{Ni}$ & $\% \mathrm{Cr}$ & $\%$ Мо & \\
\hline 0,011 & 0,029 & $0,098 \mathrm{R}$ & 0,050 & \\
\hline
\end{tabular}

The welded samples are square plates, of 100 $\mathrm{mm}$ side, and the welded joint side was prepared with single V-groove configuration. Welding was accomplished by the Shielded Metal Arc Welding (SMAW) process using an E7018 electrode, 3,2 mm in diameter. The joint was filled with single-pass and two-pass in order to obtain HAZ of different sizes. Table 2 shows the welding parameters used, the NP: Number of passes, SP: number step, V: tension, I: current, v: speed of welding, HI: heat input.

Table 2. Welding parameters used in samples.

\begin{tabular}{|c|c|c|c|c|c|}
\hline $\mathbf{N P}$ & $\mathbf{S P}$ & $\mathbf{V}(\mathbf{V})$ & $\mathbf{I}(\mathbf{A})$ & $\begin{array}{c}\mathbf{v} \\
\mathbf{m m} / \mathbf{s}\end{array}$ & $\mathbf{H I} \mathbf{J} / \mathbf{m m}$ \\
\hline 1 & 1 & $27-32$ & $160-165$ & 2,3 & $1502-1837$ \\
\hline 2 & 1 & $20-22$ & $108-115$ & 3,07 & $619-659$ \\
\cline { 2 - 6 } & 2 & $20-22$ & $108-115$ & 2,10 & $822-963$ \\
\hline
\end{tabular}

In order to obtain a flat surface, the weld excess was removed by grinding with a $0,05 \mathrm{~mm}$ pass on each step and $0,03 \mathrm{~mm}$ on the last step. For microstructure characterization, the weld cross section was removed from the welded joint and metallographically prepared. It was grounded by means of a 180-1000 mesh using grinding paper and then polished through $1 \mu \mathrm{m}$ diamond paste. Afterwards, the surfaces were chemically attacked by $2 \%$ nital and, observed under an optical microscope. The size zones were measured with a rule at low magnification. Microhardness measurements were made in the cross section, at a point located $1 \mathrm{~mm}$ below the surface, from the center of the string to a distance of $15 \mathrm{~mm}$, at each $1 \mathrm{~mm}$. A Vickers Indentation Hardness Testers, with a 100g load, was used. 
The schema of the MBN equipment used in this work is shown in Figure 1. The equipment has three basic sub-systems: a sensor-excitor assembly compound by a yoke coil with 250 turns and a commercial coil used in floppy disk, the signal conditioner and the acquisition data treatment system. A Kepco BOP 20-20 D bipolar source generates a variable current that passes through the yoke coil, increasing to a variable magnetic field in the magnetic yoke (12500 $\mathrm{A} / \mathrm{m}$ ) with a $1 \mathrm{~Hz}$ frequency. This magnetic field was in parallel direction to the welded joint. The Kepco source current is controlled by a sinusoidal wave generated by a microcomputer and sent to the source by the acquisition system D/A output. In the conditioner, the signal passes by a band pass filter (from 1 to $100 \mathrm{kHz}$ ). A variable gain amplifier then amplifies it. Data are acquired using a 12-bit data acquisition board, with sampling frequency of $200 \mathrm{kHz}$. Five MBN signals were measured in each point.

The maximum peak value, the average of MBN pulses with amplitude higher that $80 \%$ of the maximum value (called here, the maximum threshold), the rms (root mean square) and the envelope rms were calculated in the time domain parameters, while the spectrum rms, for the $0-3 \mathrm{kHz}, 0-10 \mathrm{kHz}, 10-30$ $\mathrm{kHz}, 30-60 \mathrm{kHz}, 60-85 \mathrm{kHz}$ e $85-100 \mathrm{kHz}$ bands, were calculated in the frequency domain. Maps of the surfaces, related to the microstructure state were generated.

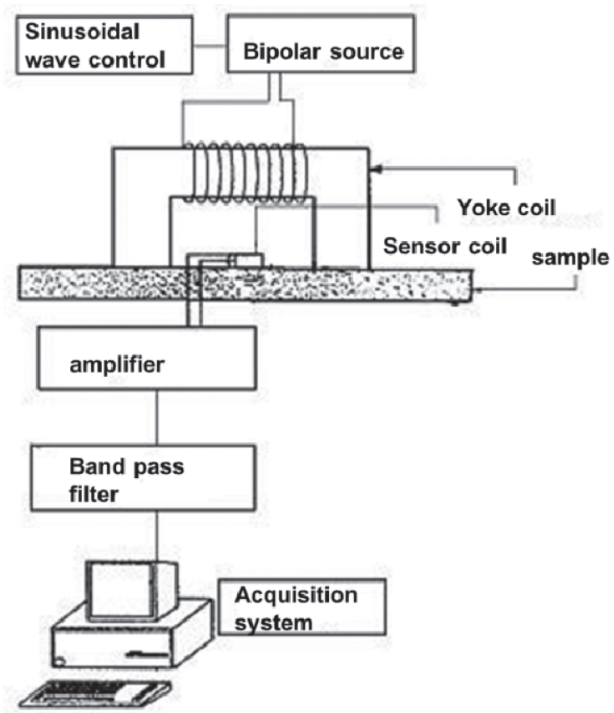

Figure 1. Scheme of the MBN measurement system.

\section{RESULTS AND DISCUSSION}

\section{Microstructure Analysis}

The zone sizes measurements in different welded samples are presented in Table 3.

Table 3. Welded joint zone sizes measured from the center of weld.

\begin{tabular}{|c|c|c|}
\hline Sample & $\begin{array}{c}\text { Fusion zone } \\
\text { width }(\mathbf{m m})\end{array}$ & $\begin{array}{c}\text { HAZ width } \\
(\mathbf{m m})\end{array}$ \\
\hline Single- pass & 5 & 5 \\
\hline Two- pass & 4 & 2 \\
\hline
\end{tabular}

Figure 2 shows the microstructures corresponding to the single-pass sample. These structures also represent those of the second pass for the two-pass sample. At the fusion zone (Figure 2a) there exists a typical solidification microstructure constituted by primary ferrite, in the grain boundary, and also polygonal, with nucleated Widmanstätten ferrite in the grain boundary. Inside the grain, acicular ferrite with low pearlite content was found in the gap between needles. In the coarsened grain region (Figure 2b), the microstructure consists of grain boundary ferrite and Widmanstätten ferrite. The grain is refined, becoming polygonal, as the distance between the weld centerline increases. This is due to the lower maximum temperatures reached in this area, which avoids austenitic grain growing, and also due to the slower cooling rates, which avoids acicular microstructure formation. In the middle grain region, the microstructure consists of ferrite with low pearlite content. In the refined grain region (Figure 2c), although the maximum temperatures have attained that of austenitic, the austenitic grain was unable to grow and the cooling rate was lower, making the microstructure basically composed of polygonal ferrite and pearlite. The intercritical zone has been heated above the lower critical temperature and partially transformed to austenite that retransformed to ferrite plus pearlite during cooling, the resulting microstructure being small pearlite colonies immersed in a ferrite matrix (Figure 2d). Adjacent to this last zone it is the region that contains non-affected parent metal (Figure 2e), where the reached maximum temperatures have been below the $\mathrm{A}_{1}$ austenitic temperature. This has impeded phase transformation. The microstructure consists of ferrite and pearlite. 

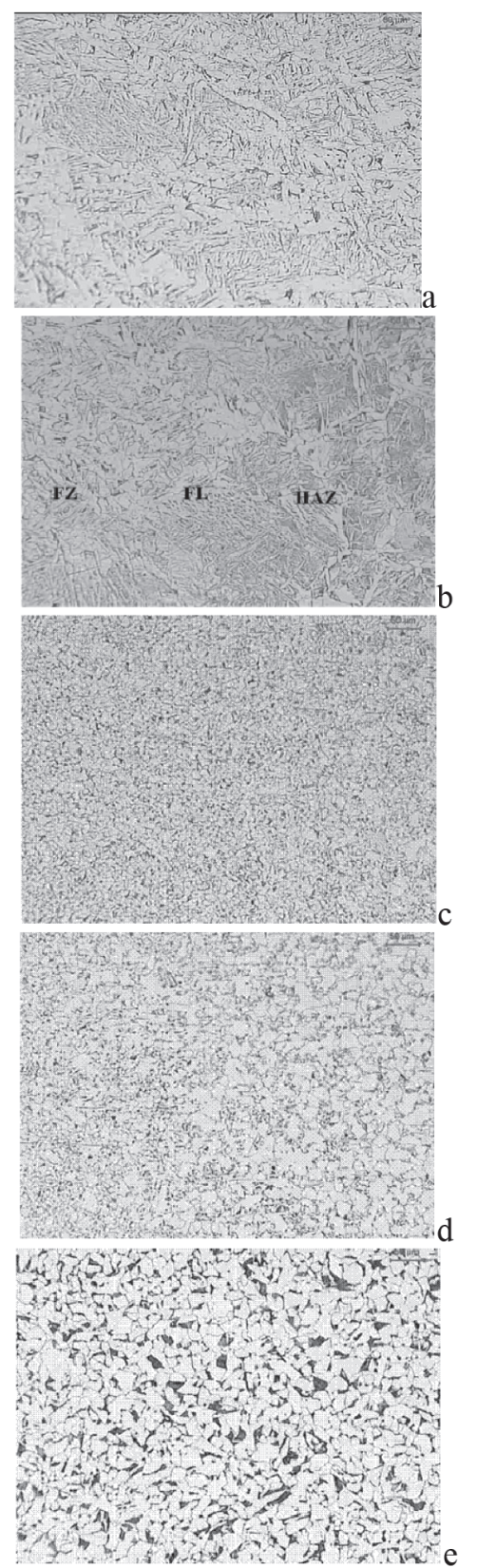

Figure 2. Typical welded joint microstructures (in clockwise sense) a) fusion zone (FZ), b) coarsened grain zone, c) fine grain zone, d) partial transformation zone, e) non-affected base metal.

Figure 3 shows the micro-hardness profiles of welded samples. In the fusion line, hardness is higher due to acicular microstructure. The hardness value decreases until the HAZ end, where it reaches a

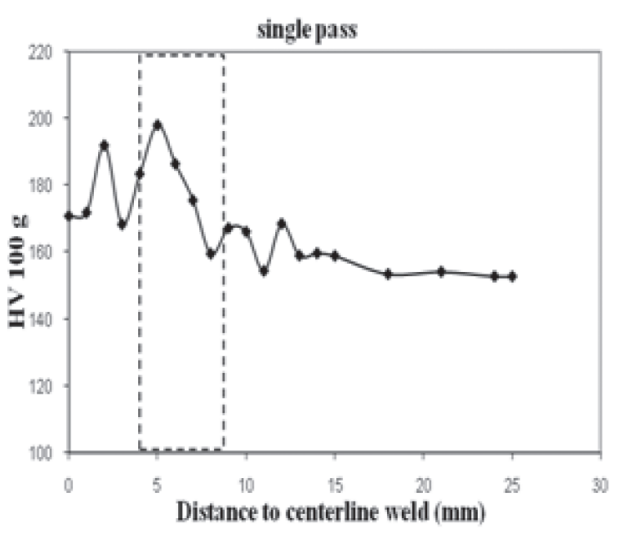

$\mathrm{a}$

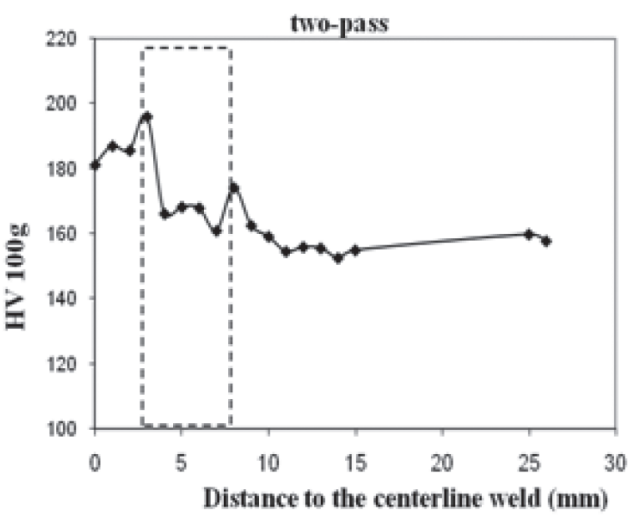

b

Figure 3. Micro-hardness profile. a) single-pass sample, b) two-passes sample.

minimum, and then raises a little to fall again until stabilization at the base metal.

MBN measurements were made in the single-pass and two-pass sample surfaces, along two lines, transversal to the bead weld, from the centerline weld to the parent metal. These lines are named L1 and L2. In each measured point, sometime domain parameters such as maximum value, the maximum threshold, the rms and the envelope rms were calculated. All of them showed the same behavior, the difference among multiple parameters being only their amplitudes.

Figure 4 presents the MBN rms obtained on these lines for single-pass and two-pass samples.

From Figure 4, it is clear that the curves present similar behavior. There exists a minimum of MBN 


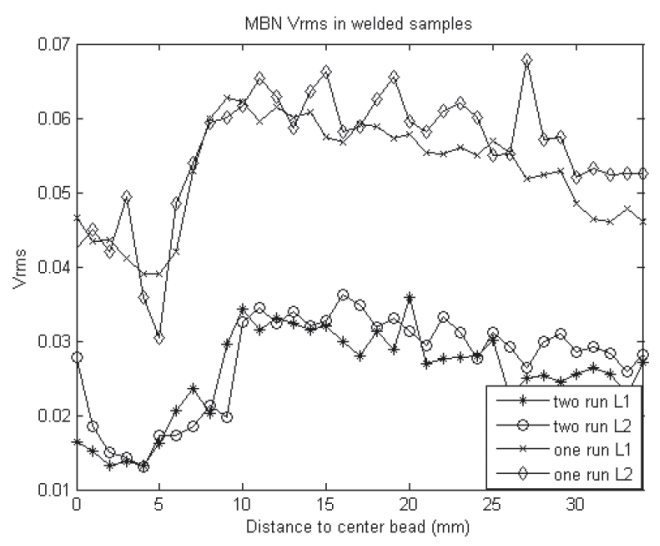

Figure 4. Values of the rms through the welded joint in single-pass and two-passes samples.

rms, located at $5 \mathrm{~mm}$ for single-pass samples, and at $4 \mathrm{~mm}$ for two-pass samples. These values correspond to the fusion line. From this point on, the MBN parameter value increases, reaching a maximum at $10 \mathrm{~mm}$, for the single-pass sample, which corresponds to the end of the HAZ. In the two-passes sample, the MBN parameter increases until the distance of $7 \mathrm{~mm}$, which also corresponds to the HAZ end, and then decreases to rise again until stabilization.

After welding, in addition to microstructural changes, residual stresses are developed. In fusion welding region, these residual stresses consist of a tensile stress in the weld metal itself, falling away parabolically to zero a short distance from the weld boundary, with a compressive stress in the outer part of the plate [15]. In this research, measurements of residual stress in transversal direction to bead plate were made by X-ray diffraction (DRX) technique. Results show compressive residual stresses from depth of $10 \mu \mathrm{m}$, which is caused by the grinding process.

Figure 5 presents the Vrms of MBN measurements, in several frequency bands. In all these frequency bands, the MBN signal presents the same tendency with the distance from the bead center, according to the microstructural evolution, and there is no correlation with the residual stresses measured. The rms spectrum amplitude value has the biggest amplitude. The rms value in a frequency band represents the energy of the signal in this band.
Therefore, it is expected that the rms spectrum amplitude value to be greater than the rms band pass values. The similar evolution of the rms band-pass values seem to indicate that that the main information in the signal is distributed broadband, and no scale factor is presented in the MBN behavior.

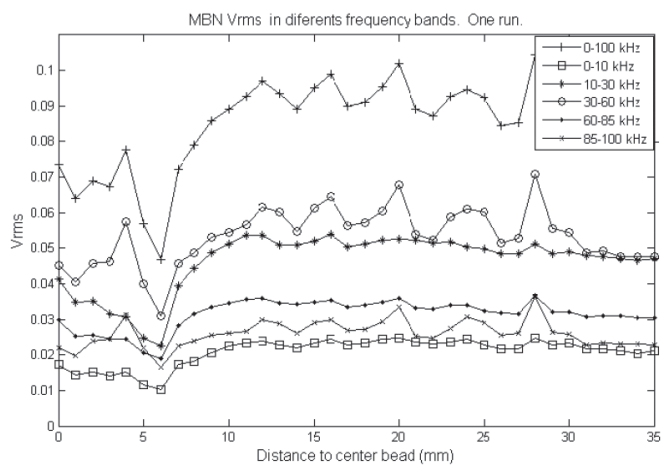

a

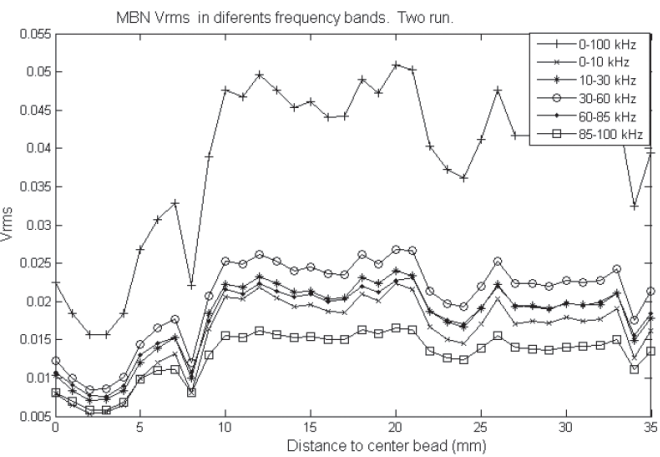

b

Figure 5. Values of the rms in different frequency bands. a) single-pass sample, b) twopasses sample.

\section{Relation of the microstructure and micro-hardness with MBN measurements}

In section 2, it was shown that the microstructure in the welded zone changes as the distance from the centerline weld increases, which is a consequence of different thermal cycles experienced in each point of the material. In this context, the microstructural variation makes the magnetization process different in each region, as a consequence of different interactions happening between domain wall movements and pinning sites.

In the fusion zone, that goes from zero to $5 \mathrm{~mm}$ in the single-pass sample and to $4 \mathrm{~mm}$ in the twopasses sample. The microstructure is heterogeneous, which is reflected in fluctuations on the hardness 
values, as well as in the Barkhausen parameters (Figures 3, 4, and 5).

Regarding the HAZ hardness variation, as shown in Figure 3, a reduction in the hardness up to the HAZ end was observed, as well as in the single-pass and the two-pass samples.

Next to the fusion line, in the coarsened grain region, the cooling rate is very high, which favors the formation of ferrite with acicular morphology as well that of fine pearlite, since high cooling rate does not allow the thickening of cementite lamellae in pearlite. These two microstructures make the HAZ region the one of biggest hardness. It was in the same region that the smallest MBN signal parameter was obtained. This fact is in conformity with what is reported by Moorthy [3] and by Mitra [22], e.g. that the grater the hardness values the smaller the MBN. After [3] this behavior is due to the fact that softer microstructures favor domain walls displacements while stiffer microstructures complicate their movement. In the acicular microstructure, the amount of dislocation is bigger and acts as a barrier to wall movements, making the MBN emission low. On the other hand, cementite lamellae also act as domain wall movement barriers, being the pinning force still bigger in the cementite lamellae that are parallel to the domain walls.

As the distance to the melting line rises, the cooling rate diminishes favouring a change in the ferrite acicular morphology that becomes polygonal with the presence of thickener pearlite colonies. A reduction in the ferrite and pearlite grain sizes can be also observed. These microstructures present lower hardness. In the intermediary grain size region, the amount of grain boundaries increases and also that of moving domain walls, producing greater MBN emission. For the small grain size, there are a great number of very small domains, and a big grain boundary area, that favors the nucleation of new domains when magnetization is reversed. Thus there is a greater amount of moving domain walls, which produces greater Barkhausen's emission [23]. On the other hand, the inexistence of acicular structure makes the quantity of dislocations lower, thus reducing the number of barriers to the domain movement and facilitating domain wall movements, which produces a greater Barkhausen emission.
The partially transformed region, at the HAZ end, corresponds to the maximum value of the MBN parameter, that is related to the distance of $10 \mathrm{~mm}$ and of $7 \mathrm{~mm}$, for respectively the single-pass and two-passes samples. The microstructure has the size of the biggest ferrite grain and, therefore, a smaller amount of domain walls and of grain boundaries act as barriers to movement. Additionally, there is also a great amount of small pearlite colonies in this region. The interaction between the reduced quantity of moving domain walls and the great amount of fine pearlite colonies immersed in the ferric matrix, acting as weaker barriers to movement, generate the biggest MBN value.

As observed past the HAZ end in the base metal, the $\mathrm{MBN}$ rms reduction is due to the grain size, which is thicker than the one reached by the grains in the closest HAZ region. As a consequence, the past HAZ presents a smaller number of moving domain walls with few barriers to movement.

\section{Welded joint MBN surface maps}

The surface maps of the welded joints were plotted with parameters obtained in the frequency and time domains. Figure 6 a shows the rms map in the time domain, as an example for the one-pass sample, while Figure $6 \mathrm{~b}$ shows the rms map in the 10-30 $\mathrm{kHz}$ band.

In the region between 0 and $10 \mathrm{~mm}$ there is a zone of great MBN variation, which corresponds to the welded zone (e.g. the melting zone and the HAZ). From the distance of $10 \mathrm{~mm}$ on, there is a region of more homogeneous MBN values that represent the base metal. In the melting zone, the MBN values reduce until a minimum, where the melting limit is located. From this limit on, the MBN values increase again up to the MBN maximum value, which corresponds to the HAZ end. Finally, after this maximum, MBN values reduce lightly up to that of the homogenous base metal.

\section{CONCLUSIONS}

The conclusions of the present study can be summarized as follows:

It is possible to monitor the HAZ in real welding of single-pass and two-pass by means of the Magnetic Barkhausen Noise. 


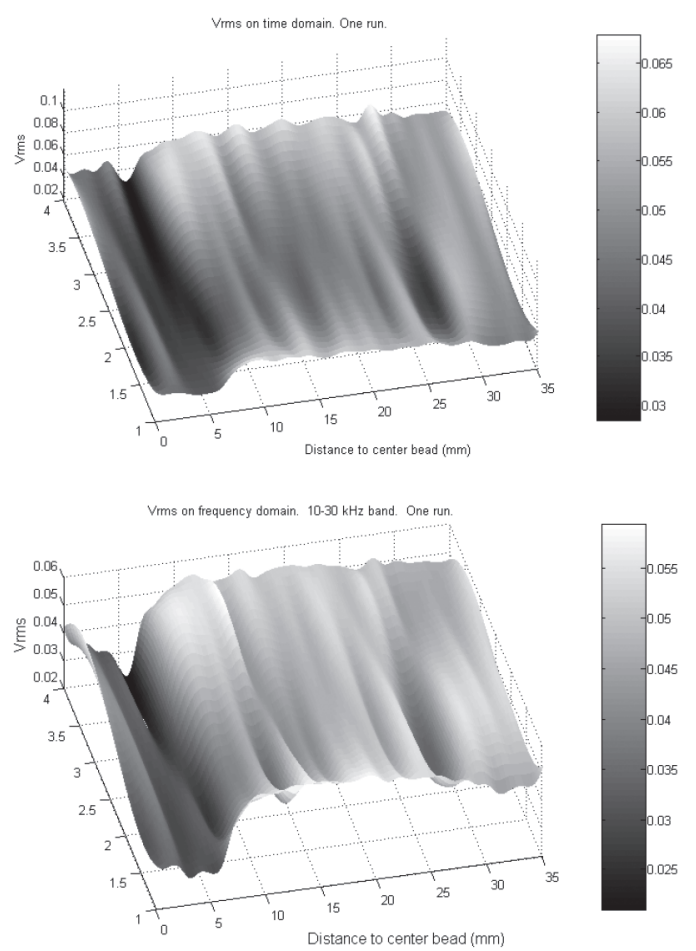

Figure 6. MBN surface maps. a) rms in the time domain. b) Spectrum rms in the 10-30 $\mathrm{kHz}$ band.

In the heat-affected zone, there are structural changes in morphology, grain size and hardness. These changes were detected by the MBN parameters. In the melting zone, the microstructure is heterogeneous. As a consequence, there is fluctuation in the MBN parameters values. The melting line is the region that displays the smallest MBN value, corresponding also to the greatest hardness value. As the hardness decreases from the grain-growing region to the refined grain region, the MBN parameters value increases.

A highly relevant parameter related to the microstructure variation in the MBN monitoring of carbon steel welded joints was not present. Both analyses in time and frequency domains were adequate. It is possible to conclude that, from the analyzed time domain parameters, the values of the rms and envelope rms are those that represent best the microstructural changes.

Regarding the used frequency parameters, all of them showed adequately the microstructural changes in the fusion zone and in the heat-affected zone.

\section{ACKNOWLEDGEMENTS}

The authors wish to thank the Brazilian agency CAPES and Universidad de Antioquia's "Estrategia de Sosteniblidad 2014-2015” program, (Colombia) for their financial support.

\section{REFERENCES}

[1] D.C. Jiles. "Dynamics of domain magnetization and the Barkhausen effect". Czechoslovak Journal of Physics. Vol. $50 \mathrm{~N}^{\circ}$ 8, pp. 893988. 2000.

[2] I. Altpeter. "Nondestructive evaluation of cementite content in steel and white cast iron using inductive Barkhausen noise". Journal of Nondestructive Evaluation. Vol. $15 \mathrm{~N}^{\mathrm{o}} 2$, pp. 45-60. 1996.

[3] V. Moorthy, B.A. Shaw and J.T. Evans. "Evaluation of tempering induced changes in the hardness profile of case-carburised EN steel using magnetic Barkhausen noise analysis". NDT\&E international. Vol. 36, pp. 43-49. 2003.

[4] A. Dhar and D.L. Atherton. "Influence of Magnetizing Parameters on the Magnetic Barkhausen Noise" IEEE Transactions on Magnetics. Vol. 28 No 6, pp. 3363-3366. 1992.

[5] L.R. Padovese, J. Capó e J. Anglada-Rivera. "Medição da tensão mecânica em aço carbono através da emissão magnética de Barkhausen". XIX Congresso Nacional de Ensaios Não Destrutivos. São Paulo, Brasil. 2000.

[6] R. Ranjan, D. Jiles and P.K. Rastogi. "Magnetic properties of decarburized steels: an investigation of the effects of grain size and carbon content". IEEE Transactions on Magnetics. Vol. 23 No 3, pp. 1869-1876. 1987.

[7] C. Gatelier-Rothea, P. Fleischmann, J. Chicois and R. Fougeres. "Role of microestructural states on the level of Barkhausen noise in pure iron and low carbon iron binay alloys". Nondestructive Test Evaluation. Vol. 8-9, pp. 591-602. 1992.

[8] J. Capó-Sanchez, L.R. Padovese y C.P. SernaGiraldo. "Utilización del efecto Barkhausen en el análisis estructural de muestras de acero al carbono". II Congresso Nacional de 
Engenharia Mecânica. João Pessoa, Brasil. 2002.

[9] J. Capó-Sánchez, L.R. Padovese e C.P. Serna-Giraldo. "Medição do ruído magnético Barkhausen em aços carbono". 57 Congresso anual da ABM Internacional. São Paulo, Brasil. 2002.

[10] J. Kameda and R. Ranjan. "Nondestructive evaluation of steels using acoustic and magnetic Barkhausen signals-I. Effect of carbide precipitation and hardness". Acta Metallurgica. Vol. $35 \mathrm{~N}^{\mathrm{o}} 7$, pp. 1515-1526. 1987.

[11] J. Capó-Sánchez, J.A. Pérez Benítez, L.R. Padovese and C.P. Serna-Giraldo. "Dependence of the Barkhausen Magnetic Emission with carbon content in commercial steel". Journal of Materials Science. Vol. 39, pp. 1367-1370. 2004.

[12] L.B. Sipahi. "Overview of applications of micromagnetic Barkhausen emissions as noninvasive material characterization technique". Journal Applied Physics. Vol. 70 $\mathrm{N}^{\circ}$ 10, pp. 6978-6980. 1994.

[13] J.Anglada-Rivera, L.R. Padovese and J. CapóSánchez. "Magnetic Barkhausen noise and hysteresis loop in commercial carbon steel: influence of applied tensile stress and grain size". Journal of Magnetism and Magnetic Materials. Vol. 231, pp. 299-306. 2001.

[14] H. Granjon. "Fundamentals of Welding Metallurgy". Abington Publishing. Cambridge, England. 1991.

[15] J.F. Lancaster. "Metallurgy of Welding". Chapman \& Hall. London, England. 1994.

[16] V. Moorty, S. Vaidyanathan, K. Laha, K. Jayakumar, Rao K. Bhanu Sankara, Raj Baldev. "Evaluation of microstrutures in 2,25Cr-1Mo and 9Cr-1Mo steel weldments using magnetic Barkhausen noise". Materials Science and Engineering". Vol. A231, pp. 98104. 1997.
[17] J.H. Kim, D.G. Park, C.I. Ok, E.P Yoon and J.H. Hong. "Effect of microestructure on magnetic Barkhausen noise level in the weld HAZ of an RPV steel". Journal of Magnetism and Magnetic Materials. Vol. 196-197, pp. 351-353. 1999.

[18] D.G.-Park, C.G. Kim and J.H. Hong. "Microestructural dependence of Barkhausen noise and magnetic relaxation in the weld HAZ of an RPV steel". Journal of Magnetism and Magnetic Materials. Vol. 215-216, pp. 765-768. 2000.

[19] V. Moorty, Vaidyanathan, T. Jayakumar and R. Baldev. "Evaluation of post-weld heat treatment in 2, S 25Cr-1Mo steel tube to tube sheet welded joints using magnetic Barkhausen noise measurement". Materials Science and Technology. Vol. $13 \mathrm{~N}^{\circ} 7$, pp. 614-617. 1999.

[20] C. Lachmann, T. Nitschke-Pagel and H. Wohlfahrt. "Characterisation of residual stress Relaxation in Fatigue Loaded Welded Joints by X-Ray Diffraction and Barkhausen Noise Method". Materials Science Forum. Vol. 347-349, pp. 374-379. 2000.

[21] C. Lachmann, T. Nitschke-Pagel and H. Wohlfahrt. "Nondestructive characterization of residual stress relaxation and fatigue processes in cyclically loaded welded joints". Proceedings of the $6^{\text {th }}$ international conference on residual stress. Oxford UK. 2000.

[22] A. Mitra, M.R. Govindaraju and D.V. Jiles. "Influence of microstructure in micromagnetic Barkhausen emissions in AISI 4140 steel. IEEE Transactions on Magnetics. Vol. 31 $\mathrm{N}^{\circ} 6$, pp. 4053-4055. 1995.

[23] D.W. Kim and D Kwon. "Quantification of the Barkhausen noise method for the evaluation of time-dependent degradation". Journal of Magnetism and Magnetic Materials. Vol. 257, pp. 175-180. 2003. 